\title{
Highly Branched Cyclic Dextrin and its Ergogenic Effects in Athletes: A Brief Review
}

Short Review

Dylan Wilburn ${ }^{1}$, Steven Machek $^{1}$, Ahmed Ismaeel ${ }^{2}$

${ }^{1}$ Exercise \& Biochemical Nutrition Laboratory, Department of Health, Human Performance, and Recreation, Baylor University, Waco, TX.

${ }^{2}$ Department of Biology, Baylor University, Waco, TX.

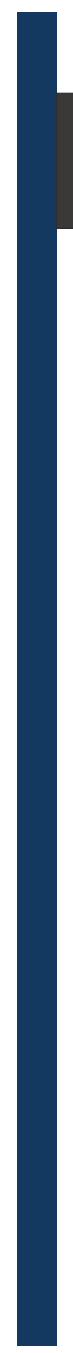

\section{Open Access}

Published: August 13, 2021

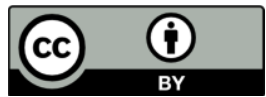

Copyright, 2021 by the authors. Published by Pinnacle Science and the work is licensed under the Creative Commons Attribution $4.0 \quad$ International License. To view a copy of this license, visit http://creativecommons .org/licenses/by/4.0/

Journal of Exercise and Nutrition: 2021, Volume 4 (Issue 3): 15

ISSN: 2640-2572

\begin{abstract}
Highly branched cyclic dextrin (HBCD) is a relatively new carbohydrate source that has gained much popularity in sports nutrition supplements, quickly becoming one of the most popular sports and fitness supplements globally. Due to its high molecular weight and low osmolality, HBCD is thought to provide an ergogenic advantage over other carbohydrate sources via faster gastric emptying and faster absorption. The purpose of this brief review is to explore performance claims and implications of $\mathrm{HBCD}$ use. We provide rationale for recommended use based on results of scientific studies conducted in both animals and humans.
\end{abstract}

Key Words: Carbohydrate, Glucose, Exercise

Corresponding author: Ahmed Ismaeel, ahmed ismaeel@,baylor.edu

\section{Introduction}

Highly branched cyclic dextrin (HBCD), often referred to by its trade name Cluster Dextrin, is an example of a carbohydrate with a high molecular weight and a low osmolality $^{1}$. In recent years, HBCD has received much attention as a "unique, cutting edge" carbohydrate supplement. According to several online supplement retailers, it is quickly becoming one of the most popular sports and fitness supplements in the world, and marketing claims describe HBCD as the "gold standard" of recovery and performance drinks ${ }^{2}$. HBCD is widely being used as a pre-, intra-, and/or post-workout supplement by individuals ranging from recreational to professional and elite weight lifters, bodybuilders, and endurance athletes ${ }^{2}$.

Notably, it has been well-established that prolonged exercise is limited by the availability of muscle and liver glycogen stores ${ }^{3-7}$. These stores are enhanced with increased carbohydrate intake 3 . The rate of glycogen synthesis has also been shown to be highest in muscles in which glycogen has been heavily depleted ${ }^{8-11}$. Furthermore, the synthesis of glycogen is dependent on several factors: glucose transport across the intestinal mucosa and the sarcolemma, as well as on enzymes responsible for glycogenesis ${ }^{12}$. Numerous studies have shown peri-workout carbohydrate supplementation to be beneficial ${ }^{13-15}$. Research has left little doubt about pre-, peri-, and post-exercise carbohydrate supplementation and its impacts on fatigue attenuation, improved performance, muscle glycogen sparing and restoration, as well as supporting blood glucose maintenance in both males and females. Furthermore, accompanying elevated insulin levels have also 
been shown to increase protein synthesis, decrease recovery time, reduce force sensation, enhance motor skills, and improve mood, along with peripheral and central nervous system function ${ }^{13-15}$. The International Society of Sports Nutrition recommends an intake of $\sim 50 \mathrm{~g}$ of carbohydrate 30 to $60 \mathrm{~min}$ prior to exercise, $0.7 \mathrm{~g}$ of carbohydrate $/ \mathrm{kg} / \mathrm{hr}$ during prolonged exercise training, and $1 \mathrm{~g} / \mathrm{kg}$ carbohydrate within $30 \mathrm{~min}$ after exercise ${ }^{16}$.

Key studies have also shown that fluid balance plays a key role in maintenance of optimal function during activities that lead to large fluid loss ${ }^{17}$. It has been shown that fluid loss of as little as $2 \%$ of bodyweight can decrease endurance performance, and a $4-5 \%$ loss of bodyweight can impair physical function ${ }^{17}$. Water lost as sweat from the blood as well as intracellular and interstitial pools can cause reduction in circulatory capacity, cooling, and exercise efficiency ${ }^{17}$. Therefore, drinking fluids during exercise, especially when it is prolonged, is advised for optimal performance and wellbeing. Notably, various carbohydrate solutions are often used to replace sweat loss during training or competition ${ }^{18}$.

The narrow size distribution, high solubility in water, low propensity for retrogradation (as other starch molecules realign themselves causing the liquid to gel when the solution is cooled or left at a lower temperature long enough), and lack of taste and smell all add to the suitability of HBCD as an ergogenic sports drink compared to other carbohydrate supplements. Performance claims of HBCD include the ability to help boost exercise endurance, accelerate performance, kick-start recovery post-workout, and circumvent cramping. Nutrient claims include that HBCD can be used to help reach a demanding high-carbohydrate intake for the day, enhance nutrient absorption, enhance muscle nutrient delivery, and help optimize glycogen repletion. Therein, the purpose of this short review is to explore performance claims and implications of HBCD use. This review begins with a discussion of the structure and manufacture of HBCD. This is followed by a discussion of scientific studies of HBCD in both animal models and in humans.

\section{Structure}

HBCD is a branched cyclic oligosaccharide with structural units consisting of $\alpha$-D-glucose monomers (Figure 1). Its molecular weight ranges from 30,000 to $1,000,000 \mathrm{~g} / \mathrm{mol}$, and its mean molecular mass is $160,000 \mathrm{Da}$. HBCD molecules contains short linear chains of $\alpha-(1,4)$ linked glucose units with branching via $\alpha-(1,6)$ glucosidic bonds. The cyclic alpha glucan moiety of the cyclic dextrin is linked to the adjacent branched cluster via an $\alpha-(1,6)$ glucosidic bond. The cyclic portion of the HBCD molecules consists of 16 to $100 \alpha$-linked glucose units. The empirical formula of $\mathrm{HBCD}$ is $\left(\mathrm{C}_{6} \mathrm{H}_{10} \mathrm{O}_{5}\right)_{\mathrm{n}}$ similar to glycogen ${ }^{1}$.

Figure 1. Structure of HBCD. Adapted from FDA GRAS ${ }^{1}$.

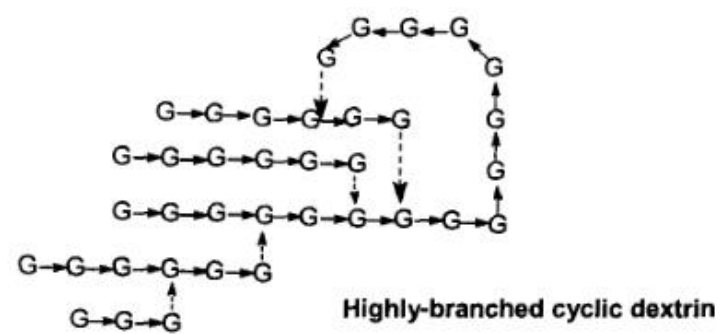

\footnotetext{
$\rightarrow$ alpha-1,4-linkage, $\rightarrow \rightarrow$ alpha-1,6-linkage

$\mathrm{G}=$ glucose unit
}

The manufacture of HBCD begins with unmodified food starch from waxy corn, predominantly in amylopectin form. The starch is then enzymatically hydrolyzed with $\alpha$-amylase derived from the bacteria Bacillus subtilis. This results in clustered oligosaccharides of short linear $\alpha-(1,4)$ glucose chains interlinked via $\alpha-(1,6)$ bonds. The second enzymatic step is carried out by $1,4-\alpha-\mathrm{D}$-glucan branching enzyme from Bacillus stearothermophilus, which leads to cyclization via intramolecular transglycosylation. The partially degraded maize starch is a white, odorless powder ${ }^{1}$.

\section{Safety Evaluation and Toleration}

HBCD has been on the market in Japan since $2002^{19}$. To expand its marketability outside of Japan, HBCD was investigated for digestibility and potential toxicity ${ }^{19}$. In vitro, it was readily hydrolyzed to maltose and maltotriose by 
human salivary amylases and porcine pancreatic $\alpha$-amylases. Incubation of HBCD with a rat intestinal homogenate containing digestive enzymes resulted in the formation of maltose, maltotriose, maltoteraose, and glucose when incubated for a longer period, all normal and safe products of carbohydrate digestion ${ }^{19}$. In an acute toxicity study, a single HBCD dose of $2 \mathrm{~g} / \mathrm{kg}$ bodyweight was orally administered to rats and did not result in mortality, signs or symptoms of toxicity, or any abnormalities upon autopsy. In an Ames assay (which uses bacteria to test whether a chemical can cause mutation in the DNA of a test organism), HBCD was shown to be non-mutagenic with or without metabolic activation. Furthermore, the branching enzyme involved in the synthesis of the molecule was tested for safety. There was no acute toxicity seen with oral administration of the enzyme to rats, and the enzyme was nonmutagenic in a mammalian cell mode ${ }^{19}$. Based on the lack of any safety concerns given that modified food starches are prevalent constituents of the human diet with a long history of safe use in food and the efficient digestion to glucose, the FDA granted HBCD GRAS status (indicated for safe and suitable consumption). As of 2010, HBCD has been excluded from the definition of a food additive and has been available for marketing and sale without promulgation of a food additive regulation in the United States ${ }^{1}$.

It is also very important for a sports beverage to be well-tolerated by the stomach and not cause any GI disorders. To investigate this, a study was conducted where subjects consumed the same meal 3 hours before exercise and were then given either test fluids based on HBCD, dextrose, glucose, or water as a control immediately before exercise ${ }^{20}$. Subjects were asked to assess feelings of flatulence every 5 minutes after consuming the beverage by rating the feeling of remaining fluid using a 6-point scale, with 5 representing a feeling of $100 \%$ of the test fluid remaining in the stomach, and 0 for no fluid being present; the number of belches was also recorded. The HBCD sports drink was associated with a lower flatulence value than glucose and dextrose from 15 minutes after ingestion to the end of the study ${ }^{20}$. The HBCD-based sports drink also induced the fewest belches, (9 compared to 23 and 24 for glucose and dextrose, respectively). Therefore, a significant attenuation of GI disorders was suggested as a result of HBCD supplementation $^{20}$.

\section{Gastric Emptying Time}

Osmolality is the measure of the moles or osmoles of solute per $\mathrm{kg}$ of solvent. A low osmolality and low osmotic pressure gradient can allow for rapid emptying of a solution from the stomach ${ }^{21}$. On the other hand, a solution with high osmolality may delay gastric emptying and delay the release of glucose from the intestine. Importantly, since blood glucose concentrations depend on the release of glucose to the intestine, transport over the intestinal mucosa in to blood, and subsequent uptake into the muscle, carbohydrates with a low osmolality may be more effective for providing energy during exercise and expediting glycogen synthesis post-training ${ }^{21}$.

To test this, a randomized, controlled crossover experiment was conducted to compare rates of muscle glycogen synthesis during the first 2 and 4 hours after the ingestion of two energy-equivalent carbohydrate solutions: with high or low osmolality ${ }^{21}$. Specifically, the high osmolality drink was composed of monomeric and oligomeric glucose units from maize starch with a molecular mass of $500 \mathrm{~g} / \mathrm{mol}$ and an osmolality of $350 \mathrm{mOsmol}$. The low osmolality beverage was composed of large glucose polymers from potato starch with a molecular mass between 500,000 and 700,000 $\mathrm{g} / \mathrm{mol}$ and an osmolality of $84 \mathrm{mOsmol}$. With the diet standardized the day before and the morning of, participants reported to the lab on two occasions, each time performing a standard exercise routine designed to deplete as many different types of muscle fibers as possible. The exercise was followed by ingestion of a different beverage each time, randomly selecting the first condition for each participant. Both drinks contained $300 \mathrm{~g}$ of carbohydrates, given as 75 $\mathrm{g}$ immediately after and then another $75 \mathrm{~g} \mathrm{30-,} \mathrm{60-,} \mathrm{and} \mathrm{90-minutes} \mathrm{post-exercise.} \mathrm{Blood} \mathrm{samples} \mathrm{and} \mathrm{muscle} \mathrm{biopsies}$ showed that the exercise caused a reduction in muscle glycogen content in all participants and that consumption of both types of carbohydrates significantly elevated the mean muscle glycogen content. However, the mean muscle glycogen contents were significantly higher after administration of the beverage with the lower osmolality, and the mean rate of glycogen synthesis was significantly higher, especially during the first hour. There was also no difference in blood glucose or insulin concentrations, suggesting faster delivery of the lower osmolality carbohydrate solution from the intestine and faster uptake by the muscle cell ${ }^{21}$.

Likewise, HBCD is a carbohydrate known to have a low osmolality (Figure 2). A 10\% HBCD solution has an osmotic pressure of 9 mOsm, compared to 646 for $10 \%$ glucose and 117 for dextrin, a common ingredient in sports drinks. The low osmolality of HBCD has led researchers to evaluate whether this translates into shorter gastric emptying time $(G E T)^{22}$. Ten participants, both male and female, were randomly administered either water, physiological saline, or a $5 \%$ or $10 \%$ solution of HBCD, glucose, maltose, or sucrose. The relaxed cross-sectional area of the pylorus antrum (RCA) was then measured by an ultrasonic echo-image analyzer, which has been reported to be well correlated with 
gastric volume after ingestion of a drink ${ }^{22}$. The study showed that while GET increased as a function of increased solution for both HBCD and glucose, the GET for 10\% HBCD (26.7 minutes) was significantly less than that of the comparable 10\% glucose solution (39.9 minutes). HBCD also showed a lower GET than maltose and sucrose, although differences were not significant ${ }^{22}$.

Figure 2. Proposed Mechanism of HBCD's Ergogenic Potential

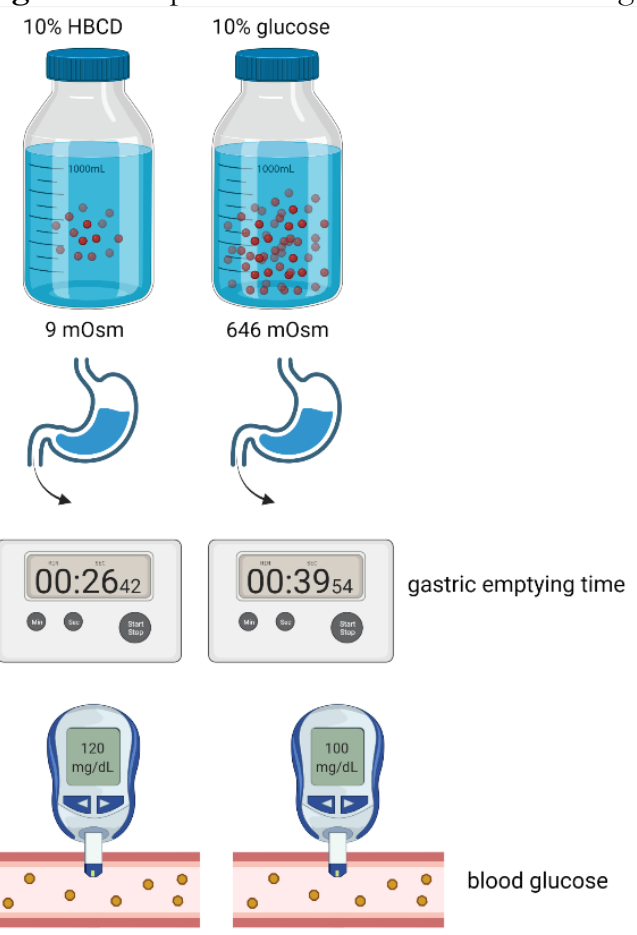

Due to a lower osmolality, HBCD results in a faster GET compared to glucose, thus resulting in faster elevated blood glucose levels.

\section{Animal Studies}

The first studies assessing the ergogenic effect of HBCD on exercise were conducted in animals. For example, to examine the effects of HBCD on endurance, researchers used an adjustable-current water pool for evaluating maximum swimming endurance of mice $^{23}$. After a preliminary test determined $500 \mathrm{mg} / \mathrm{kg}$ to be the optimal concentration for both glucose and HBCD, a solution of that dosage of either HBCD, glucose, or a water control was administered to mice 10 minutes before, 10 minutes after, or 30 minutes after the start of swimming. Interestingly, mice given a glucose solution had a $40 \%$ poorer swimming endurance than those given a solution of HBCD. The mice given HBCD 10 minutes after the beginning of the swim had significantly longer swimming times until fatigue (which was measured by failure to rise to the surface of the water for breath within 7 seconds, and often resulted in drowning). The mean swimming times to fatigue for the mice given a water, glucose, or HBCD solution were 65 , 68, and 86 minutes, respectively $(\mathrm{p}<0.05)^{23}$. It is important to note in this study, however, that researchers provided all mice with a stock diet, and they were fasted for 7 hours before administration of the solutions. In contrast, another study assessed the effect of HBCD supplementation on swimming endurance in mice under two different dietary conditions ${ }^{24}$. Specifically, mice were first fed a growth-purified diet consisting of $\sim 20 \%$ protein, $\sim 10 \%$ fat, and $\sim 70 \%$ carbohydrate for three days. Mice were then randomized to either $0.25 \mathrm{~mL}$ of a $5 \%$ HBCD solution or distilled water (volumeequated) at 10 minutes after the start of swimming, and the swimming time until fatigue was measured. Subsequently, the diet for both groups of mice then changed to a low-carbohydrate, high-fat diet $(\sim 20 \%$ carbohydrate, $\sim 20 \%$ protein, and $\sim 60 \%$ fat) for another 3 days, whereby the aforementioned supplementation and swim-to-fatigue protocol as repeated ${ }^{24}$. Notably, swimming time until fatigue was significantly higher in mice administered HBCD compared to water only when a low-carbohydrate diet was provided. No significant difference in swimming endurance was observed between the HBCD and control groups when mice were fed a high-carbohydrate diet for three days prior to testing ${ }^{24}$. These data suggest that HBCD may only be ergogenic is conditions of sub-optimal exercise carbohydrate substrate availability. 


\section{Human Studies}

The first human study evaluating the ergogenic potential of HBCD was conducted in 201425. In the study, the effect of a low dose $(15 \mathrm{~g})$ of HBCD was compared with the same dosage of maltodextrin during endurance exercise. In a double-blind, randomized, crossover experiment, participants $(\mathrm{N}=24)$ were administered one test drink on the first occasion and the other two weeks later. Participants were all healthy males between the ages of 25-39. All participants refrained from exercise the day before the experiment and consumed the same carbohydrate-rich meal the day before as well as the morning of the experiment. The exercise protocol was done at $40 \% \mathrm{VO}_{2}$ max for 30 minutes, and then at $60 \% \mathrm{VO}_{2}$ max for 90 minutes, and the test beverages were consumed at 1 hour after the start of the exercise ${ }^{25}$. During and after the exercise protocol, researchers assessed the rating of perceived exertion (RPE) as well as blood components associated with energy metabolism. The increase in RPE at 30 and 60 minutes after ingestion was significantly lower after consuming HBCD than maltodextrin $(\mathrm{p}<0.01)$. There was no difference in blood lactic acid, non-esterified fatty acids, ketone bodies, or blood insulin concentrations between the two groups. The increase in blood glucose concentrations at 30 minutes after ingestion was higher after the HBCD beverage than after the maltodextrin beverage $(5.1 \pm 2.1 \mathrm{mg} / \mathrm{dL}$ vs. $2.0 \pm 1.8 \mathrm{mg} / \mathrm{dL})$, although differences were not significant ${ }^{25}$. Nevertheless, the higher increase in blood glucose concentrations without a difference in insulin concentrations and the concomitant suppression of RPE elevation during exercise may be a HBCD-mediated extension in glucose-derived energy, commensurate with a shorter GET.

Another recent study tested the effect of HBCD on swimming endurance performance in elite, male athletes $(\mathrm{N}=7)^{26}$. Participants consumed an identical meal (60\% carbohydrate) on the day before the experiment. On the day of the trial, in a crossover fashion (at least 1-week inter-trail interval), participants were randomized to receive either $1.5 \mathrm{~g}$ carbohydrate $/ \mathrm{kg}$ bodyweight $(21 \mathrm{~g} / 100 \mathrm{ml}$ beverage, $\sim 500 \mathrm{~mL})$ from either glucose or HBCD, or $500 \mathrm{~mL}$ of water control. Following drink ingestion, participants swam 10 cycles in a swimming flume (counter-current pool). Each cycle consisted of $5 \mathrm{~min}$ swimming at $75 \% \mathrm{VO}_{2} \mathrm{max}$, followed by $3 \mathrm{~min}$ of rest. After the initial 10 cycles, participants swam at $90 \% \mathrm{VO}_{2}$ max until exhaustion, which was defined as being forced to move $1 \mathrm{~m}$ back from starting position. Interestingly, swimming time to exhaustion was almost $70 \%$ longer after receiving HBCD compared to glucose or water (HBCD: $504.4 \pm 133.3 \mathrm{sec}$, glucose: $283.7 \pm 48.3 \mathrm{sec}$, water: $309.4 \pm 73.9 \mathrm{sec}, \mathrm{p}<0.05)^{26}$. This improvement in endurance was accompanied by significantly higher blood glucose levels at several time points following the HBCD beverage compared to both glucose and water.

Strenuous exercise has been shown to suppress cellular immunity and potentially enhance host susceptibility to infections. Alterations in immune function following exhaustive exercise can lead to flu-like symptoms associated with systemic cytokine release ${ }^{27}$, and prevention of these symptoms is important to athletes. Glucose supplements have been shown to reduce stress hormone levels and cytokine concentrations and to modulate neutrophil counts and activity $^{28}$. To examine whether HBCD supplementation confers the same immunity protection, researchers investigated 7 triathletes during 2 duathlon races on the same course a month apart in a randomized, double-blind placebo-controlled cross-over design ${ }^{29}$. The effects of a 5\% HBCD-based drink were compared with those of a 5\% glucose-based drink on stress hormone levels and cytokine responses to the exercise. All participants were prohibited from taking any vitamins, minerals, herbs, supplements, or medicines affecting immune function the days leading up to the race. Additionally, participants were fed a standardized, high-carbohydrate breakfast and lunch on the race days. The test beverages were given before the race, after the first run, during cycling, after cycling, and before the second run, for a total of $2000 \mathrm{~mL}$ for each drink. Blood and urine samples were collected within 10-15 minutes after the race. In this study, the race time was not significantly different between the HBCD and glucose trials. However, lymphocyte counts and plasma noradrenaline concentrations increased significantly only after the glucose trial and not after the HBCD trial. Likewise, urine concentrations and gross excretion amounts of interleukin (IL)-8 (a pro-inflammatory cytokine) IL-10 (an immunosuppression cytokine associated with trauma), and IL-12 p40 (a pathogen protection cytokine) increased significantly only after the race in the glucose trial, but not after $\mathrm{HBCD}^{29}$. These results suggest that HBCD may help maintain blood glucose availability for a relatively long time during exhaustive endurance exercise. This external energy source may potentially work to spare stress hormone responses, which can have preventative effects on the body's stress responses. In fact, it is thought that carbohydrate supplementation during prolonged and/or intense exercise is the most effective nutritional intervention to counteract immunodepression due to the maintenance of blood glucose levels ${ }^{30}$. Table 1 summarizes the results of the human studies assessing the effects of HBCD. 
Table 1. Summary of HBCD Human Trials

\begin{tabular}{|c|c|c|c|c|c|}
\hline Article & Population & Design & Supplement & Exercise & Outcomes \\
\hline $\begin{array}{l}\text { Furuyashiki } \\
\text { et al. }{ }^{25}\end{array}$ & $\begin{array}{l}\mathrm{N}= \\
\text { healthy males }\end{array}$ & $\begin{array}{l}\text { Randomized, } \\
\text { crossover trial }\end{array}$ & $\begin{array}{l}15 \mathrm{~g} \text { HBCD vs. } \\
15 \mathrm{~g} \\
\text { maltodextrin }\end{array}$ & $\begin{array}{l}40 \% \mathrm{VO}_{2} \max \text { for } 30 \\
\text { minutes, } \\
\mathrm{VO}_{2} \max \text { for } \quad 90 \% \\
\text { minutes }\end{array}$ & $\begin{array}{l}\text { Significantly lower } \\
\text { increase in RPE with } \\
\text { HBCD }\end{array}$ \\
\hline $\begin{array}{l}\text { Shiraki et } \\
\text { al. }^{26}\end{array}$ & $\begin{array}{l}\mathrm{N}=7 \quad \text { male } \\
\text { elite athletes }\end{array}$ & $\begin{array}{l}\text { Randomized, } \\
\text { crossover trial }\end{array}$ & $\begin{array}{l}\sim 100 \text { g } \mathrm{HBCD} \\
\text { vs. } \sim 100 \quad \mathrm{~g} \\
\text { glucose } \\
\text { water }\end{array}$ & $\begin{array}{l}10 \text { cycles }(5 \mathrm{~min}, 3 \mathrm{~min} \\
\text { rest) of swimming at } \\
75 \% \mathrm{VO}_{2} \mathrm{max}, \quad 90 \% \\
\mathrm{VO}_{2} \max \\
\text { exhaustion }\end{array}$ & $\begin{array}{l}\text { Significantly longer } \\
\text { swimming time to } \\
\text { exhaustion } \\
\text { HBCD }\end{array}$ \\
\hline $\begin{array}{l}\text { Suzuki et } \\
\text { al. }{ }^{29}\end{array}$ & $\begin{array}{l}\mathrm{N}=7 \quad \text { male } \\
\text { triathletes }\end{array}$ & $\begin{array}{l}\text { Randomized, } \\
\text { crossover trial }\end{array}$ & $\begin{array}{lr}5 \% & \text { HBCD vs } \\
5 \% & \text { glucose } \\
\text { drink } & \end{array}$ & $\begin{array}{l}\text { Duathlon race }(5 \mathrm{~km} \\
\text { of running, } 40 \mathrm{~km} \text { of } \\
\begin{array}{l}\text { cycling, } 5 \mathrm{~km} \text { of } \\
\text { running) }\end{array}\end{array}$ & $\begin{array}{l}\text { Significantly lower } \\
\text { lymphocyte counts, } \\
\text { noradrenaline plasma } \\
\text { levels, and IL-8, IL- } \\
10 \text {, IL-12 p40 urine } \\
\text { concentrations with } \\
\text { HBCD }\end{array}$ \\
\hline
\end{tabular}

RPE: rating of perceived exertion

\section{Conclusions}

Based on the results of the available studies, HBCD may provide increased performance or endurance compared to other carbohydrate sources, such as maltodextrin and glucose, especially in conditions of low carbohydrate feeding $25,26,29$. Examples of performance benefits may be a reduction in RPE during strenuous activity and longer swimming time to exhaustion. However, diets sufficient in carbohydrates may negate any added benefit of HBCD supplementation. HBCD may also be beneficial to the immune system for endurance and ultra-endurance athletes. In addition, HBCD may hold greater performance benefits during whole-body exercises with higher glucose demand, such as swimming.

Due to the limited number of studies on HBCD, further research is necessary. Future studies should include larger sample sizes, female participants, and different control beverages, such as dextrose, dextrin, and maltodextrin. Additionally, upcoming investigations should assess HBCD's ergogenic effects amidst different exercise modalities, including resistance training. Furthermore, it would be interesting to assess the utility of HBCD in conditions of intentional carbohydrate depletion or limitation (i.e., bodybuilders, combat athletes, and powerlifters leading into a competition). It is important to note that due to its high cost, HBCD may not be a very practical supplement for amateur athletes or recreational exercisers. For example, the average retail price for HBCD is $\sim \$ 1.17$ per $25 \mathrm{~g}$, compared to $\sim \$ 0.22$ per $25 \mathrm{~g}$ of maltodextrin. Conversely, elite or professional athletes may benefit from the increased performance or endurance shown in some studies. Notwithstanding these caveats, this carbohydrate-based supplement is only beginning to demonstrate its utility and may prove to hold a more foundational role upon greater empirical substantiation.

\section{Acknowledgements}

Figure 2 created with Biorender.com

\section{References}

1. U.S. Food and Drug Administration C for FS and A. GRAS Notice Inventory - Agency Response Letter GRAS $\begin{array}{lllll}\text { Notice } & \text { No. GRN } & 000404 .\end{array}$ http://www.fda.gov/Food/IngredientsPackagingLabeling/GRAS/NoticeInventory/ucm327929.htm

2. Highly Branched Cyclic Dextrin (5 lb) - Canadian Protein.com. Accessed October 25, 2015. http://www.canadianprotein.com/highly-branched-cyclic-dextrin-5lb.html

3. Bergström J, Hultman E. Muscle glycogen synthesis after exercise: an enhancing factor localized to the muscle cells in man. Nature. 1966;210(5033):309-310.

4. Price TB, Sanders K. Muscle and liver glycogen utilization during prolonged lift and carry exercise: male and female responses. Physiol Rep. 2017;5(4):e13113. doi:10.14814/phy2.13113 
5. Gonzalez JT, Fuchs CJ, Betts JA, van Loon LJC. Liver glycogen metabolism during and after prolonged endurance-type exercise. Am J Physiol Endocrinol Metab. 2016;311(3):E543-553. doi:10.1152/ajpendo.00232.2016

6. Murray B, Rosenbloom C. Fundamentals of glycogen metabolism for coaches and athletes. Nutr Rev. 2018;76(4):243-259. doi:10.1093/nutrit/nuy001

7. López-Soldado I, Guinovart JJ, Duran J. Increased liver glycogen levels enhance exercise capacity in mice. J Biol Chem. 2021;297(2):100976. doi:10.1016/j.jbc.2021.100976

8. Jentjens R, Jeukendrup A. Determinants of post-exercise glycogen synthesis during short-term recovery. Sports Med Auckl NZ. 2003;33(2):117-144. doi:10.2165/00007256-200333020-00004

9. Ivy JL. Muscle Glycogen Synthesis Before and After Exercise. Sports Med. 1991;11(1):6-19. doi:10.2165/00007256-199111010-00002

10. van Loon LJ, Saris WH, Kruijshoop M, Wagenmakers AJ. Maximizing postexercise muscle glycogen synthesis: carbohydrate supplementation and the application of amino acid or protein hydrolysate mixtures. Am J Clin Nutr. 2000;72(1):106-111. doi:10.1093/ajen/72.1.106

11. Halse R, Bonavaud SM, Armstrong JL, McCormack JG, Yeaman SJ. Control of Glycogen Synthesis by Glucose, Glycogen, and Insulin in Cultured Human Muscle Cells. Diabetes. 2001;50(4):720-726. doi: $10.2337 /$ diabetes.50.4.720

12. Terjung RL, Baldwin KM, Winder WW, Holloszy JO. Glycogen repletion in different types of muscle and in liver after exhausting exercise. Am J Physiol. 1974;226(6):1387-1391.

13. Davis JM, Jackson DA. Carbohydrate drinks delay fatigue during intermittent, high-intensity cycling in active men and... Int J Sport Nutr. 1997;7(4):261.

14. Jason J Winnick JMD. Carbohydrate feedings during team sport exercise preserve physical and CNS function. Med Sci Sports Exerc. 2005;37(2):306-315. doi:10.1249/01.MSS.0000152803.35130.A4

15. Welsh RS, Davis JM, Burke JR, Williams HG. Carbohydrates and physical/mental performance during intermittent exercise to fatigue. Med Sci Sports Exerc. 2002;34(4):723-731.

16. Kerksick CM, Wilborn CD, Roberts MD, et al. ISSN exercise \& sports nutrition review update: research \& recommendations. J Int Soc Sports Nutr. 2018;15(1):38. doi:10.1186/s12970-018-0242-y

17. Craig EN, Cummings EG. Dehydration and muscular work. J Appl Physiol. 1966;21(2):670-674.

18. Von Duvillard SP, Braun WA, Markofski M, Beneke R, Leithäuser R. Fluids and hydration in prolonged endurance performance. Nutr Burbank Los Angel Cty Calif. 2004;20(7-8):651-656. doi:10.1016/j.nut.2004.04.011

19. Choi SSH, Danielewska-Nikiel B, Ohdan K, Kojima I, Takata H, Kuriki T. Safety evaluation of highly-branched cyclic dextrin and a 1,4- $\alpha$-glucan branching enzyme from Bacillus stearothermophilus. Regul Toxicol Pharmacol. 2009;55(3):281-290. doi:10.1016/j.yrtph.2009.07.011

20. Takii H, Kometani T, Nishimura T, Kuriki T, Fushiki T. A sports drink based on highly branched cyclic dextrin generates few gastrointestinal disorders in untrained men during bicycle exercise. Food Sci Technol Res. 2004;10(4):428-431. doi:10.3136/fstr.10.428

21. Aulin KP, Söderlund K, Hultman E. Muscle glycogen resynthesis rate in humans after supplementation of drinks containing carbohydrates with low and high molecular masses. Eur J Appl Physiol. 2000;81(4):346-351. doi:10.1007/s004210050053

22. Takii H, Takii (Nagao) Y, Kometani T, et al. Fluids containing a highly branched cyclic dextrin influence the gastric emptying rate. Int J Sports Med. 2005;26(4):314-319. doi:10.1055/s-2004-820999

23. Takii H, Ishihara K, Kometani T, Okada S, Fushiki T. Enhancement of swimming endurance in mice by highly branched cyclic dextrin. Biosci Biotechnol Biochem. 1999;63(12):2045-2052. doi:10.1271/bbb.63.2045

24. Ishihara K, Yamada A, Mita Y, et al. Improved swimming pool achieves higher reproducibility and sensitivity to effect of food components as ergogenic aids. J Nutr Sci Vitaminol (Tokyo). 2009;55(3):301-308. doi:10.3177/jnsv.55.301

25. Furuyashiki T, Tanimoto H, Yokoyama Y, Kitaura Y, Kuriki T, Shimomura Y. Effects of ingesting highly branched cyclic dextrin during endurance exercise on rating of perceived exertion and blood components associated with energy metabolism. Biosci Biotechnol Biochem. 2014;78(12):2117-2119. doi:10.1080/09168451.2014.943654

26. Shiraki T, Kometani T, Yoshitani K, Takata H, Nomura T. Evaluation of Exercise Performance with the Intake of Highly Branched Cyclic Dextrin in Athletes. Food Sci Technol Res. 2015;21(3):499-502.

27. Smith LL. Overtraining, excessive exercise, and altered immunity. Sports Med. 2012;33(5):347-364. doi:10.2165/00007256-200333050-00002

28. Nieman DC. Immunonutrition support for athletes. Nutr Rev. 2008;66(6):310-320. doi:10.1111/j.17534887.2008.00038.x 
29. Suzuki K, Shiraishi K, Yoshitani K, Sugama K, Kometani T. Effect of a sports drink based on highly-branched cyclic dextrin on cytokine responses to exhaustive endurance exercise. J Sports Med Phys Fitness. 2014;54(5):622630.

30. Peake JM, Neubauer O, Walsh NP, Simpson RJ. Recovery of the immune system after exercise. J Appl Physiol. 2017;122(5):1077-1087. doi:10.1152/japplphysiol.00622.2016 